\title{
LA COMPRENSIÓN DE TEXTOS DE CONTENIDO MEDIOAMBIENTAL EN ESTUDIANTES DE SÉPTIMO GRADO
}

\author{
The understanding of environmental content texts in seventh grade students
}

\author{
Dainelis Sánchez Falcón, Msc. \\ Universidad de Oriente, Cuba \\ https://orcid.org/0000-0003-3099-2365 \\ milagros.gutierrez@uo.edu.cu
}

\author{
Maribel Rodríguez Núñez, Dr. C. \\ Universidad de Oriente, Cuba \\ https://orcid.org/0000-0003-4921-7115 \\ maribelrn@uo.edu.cu
}

\author{
Milagros Gutiérrez Sánchez, Msc. \\ Universidad de Oriente, Cuba \\ https://orcid.org/0000-0001-7146-250X \\ milagros.gutierrez@uo.edu.cu
}

Palabras claves: Comprensión, Actividades, Medioambiental.

Keywords: Understanding, Activities, Environmental.
Recibido: 27 de julio de 2018

Aceptado: 22 de noviembre de 2018

\section{RESUMEN}

En el presente artículo se fundamenta la necesidad del tema y otros aspectos vinculados al mismo; en su desarrollo hace referencia a los criterios científicos en que se basa el estudio, así como una propuesta de actividades variadas y novedosas que en su conjunto pueden ser utilizadas en las clases como modelo, de forma planificada en la asignatura Español Literatura. La aplicación de las actividades resulta pertinente en tanto posibilita el tratamiento a la comprensión de textos de contenido medioambiental en estudiantes de séptimo grado en las secundarias básicas. La importancia del trabajo radica en que a partir del correcto empleo de las actividades se garantiza el desarrollo de la expresión escrita, el conocimiento de una temática social y la formación de valores. Los textos seleccionados, todos relacionados con el Medio Ambiente, contribuyen a solucionar insuficiencias existentes respecto a la comprensión de textos, lográndose además la formación de un educando con una elevada cultura general integral.

\begin{abstract}
Presently article is based the necessity of the topic and other aspects linked to the same one; in their development he/she makes reference to the scientific approaches on that the study is based, as well as a proposal of varied and novel activities that you/they can be used in the classes in its group like I model, in way planned in the subject Spanish Literature. The application of the activities is pertinent as long as it facilitates the treatment to the understanding of texts of environmental content in students of seventh degree in the basic secondary. The importance of the work resides in that is guaranteed the development of the written expression, the social knowledge of a thematic one and the formation of values starting from the correct employment of the activities. The selected texts, all related with the environment, contribute to solve existent inadequacies regarding the understanding of texts, being also achieved the formation of an educating with a high integral general culture.
\end{abstract}




\section{INTRODUCCIÓN}

La principal exigencia de la sociedad contemporánea a la escuela cubana actual es la formación de una personalidad que piense, elabore y defienda sus criterios, puntos de vistas y convicciones; amplíe sus conocimientos y los renueve de forma sistemática y autodidacta, enfrente y solucione creadoramente las tareas sociales.

Cumplir la misión antes señalada implica que la escuela se transforme en una verdadera "fragua" en la cual se forjen y consoliden cualidades propias de los adolescentes, quienes deben convertirse en sujetos y actuar como las fuerzas más activas del proceso de enseñanza-aprendizaje.

Convertir a los estudiantes en esa fuerza activa significa incorporarlos al proceso de formación de sí mismos, educarlos a través del autoeducación, enseñarlos a sentir la necesidad, la motivación y el interés por adquirir conocimientos y habilidades en el trabajo, implica desarrollar sus capacidades y potencialidades creadoras.

El mundo cambiante y dinámico, impone encarar procesos comunicativos a la par de los avances de la lingüística del texto. Sobre la base de estas ideas la escuela moderna concibe proyectos educativos que involucran a estudiantes que tienen como sustento pedagógico el conocimiento y la comprensión del mundo que los rodea.

En el contexto de la escuela cubana se emiten aspiraciones que se pretenden alcanzar y estas convierten al educando en protagonista del proceso. Entender la relación que se establece entre ellos es un punto capital del nuevo modelo que se aspira. La comprensión de textos, por ejemplo, tiene en estos momentos gran importancia en la enseñanza de la Lengua Materna e incluso en el proceso enseñanza-aprendizaje.

La comprensión de textos es uno de los componentes funcionales más importantes de la lengua y también el primero al que se le debe dar tratamiento en las clases para el desarrollo de una comunicación eficiente, por lo tanto, es necesario que se trabaje y exploten las potencialidades y mensajes que incluyen los mismos.

Es la comprensión de textos vía para el desarrollo de una educación ambiental, pues esta proporciona el desarrollo de la lectura, la interpretación; desarrolla, además, la expresión oral y escrita; el estudiante emite juicios, criterios hace valoraciones y adquiere una conciencia que le permite un cambio de comportamiento.

Se necesita sistemáticamente mejorar el aprendizaje sobre el medio que lo rodea de forma tal que se adquiera una nueva conducta en los educandos, que permita el cambio favorable de su actuación sobre el entorno ambiental. Para ello, debe tenerse en cuenta que leer es más que saber reconocer cada una de las palabras que conforman un texto determinado. Leer es ser capaz de integrar los saberes y experiencias de comprensión para entonces poder elaborar una interpretación.

Los resultados investigativos que se presentan en este artículo resultan pertinentes porque responden a la necesidad de perfeccionar cada vez más el proceso de enseñanza-aprendizaje, con énfasis en la comprensión de textos.

Resulta de interés que se aborde el aspecto referido al logro de una Educación Ambiental que posibilita bases sólidas desde las propias herramientas que brinda la asignatura Español-Literatura en los estudiantes, hasta lo particular que otras asignaturas pueden asumir desde este punto de vista.

En fin, la información contenida en el artículo aborda la comprensión de textos como uno de los componentes funcionales de la asignatura, debido a su empleo como vía para el logro de una educación dirigida al conocimiento de un tema social. Además, muestra las experiencias investigativas del trabajo de la comprensión que se brinda desde diferentes textos en vías de un aprendizaje desarrollador. Todo lo cual requirió de importantes métodos y técnicas investigativas: el análisis - síntesis, hermenéutica, análisis documental y criterio de especialistas experimentados en el tema que se aborda.

\section{DESARROLLO}

Los avances científico-tecnológicos de la era moderna posibilitan que el desarrollo social se renové a pasos agigantados; el mundo requiere de habilidades capaces de interpretarlo y transformarlo, por lo que una de las tareas fundamentales que tiene la escuela actual es hacer de sus educandos hombres que comprendan.

Es así como, se aborda el conocimiento como un proceso dialéctico desde el pensamiento concreto: sensaciones, percepciones y representaciones; así como el pensamiento abstracto (conceptos, juicios y razonamientos); y de este a la práctica social, desde lo vivencial y la experiencia creadora, analizado todo a través del proceso de enseñanzaaprendizaje. 
Atendiendo a estos elementos es que se analiza el trabajo en función de la comprensión de textos de contenido medioambiental como un proceso de apropiación de lo que para el sujeto se torna significativo, en relación con el aprendizaje de los contenidos de la asignatura Español - Literatura, de acuerdo con las normas y principios que se establecen para la Secundaria Básica.

En términos metafóricos, la vida es un gran texto conformado por otros de diversas magnitudes; solo mediante su interpretación el hombre podrá comprenderla para incorporarla a su accionar cotidiano.

Al respecto la comprensión de textos resulta relevante, a este componente se le debe conceder un tratamiento priorizado por medio de aquellas asignaturas que privilegian el estudio de la Lengua Materna.

La lingüística textual, en sus investigaciones acerca de la comunicación trabaja el texto, de igual forma se apoya en la comprensión. Así mismo, señala Eco, H. (1976: 45) que la comprensión está dirigida a que el texto "es un artificio sintáctico-semántico-pragmático cuya interpretación está prevista en su propio proyecto generativo".

De ahí que, la comprensión ha de corresponderse con las propuestas que ofrecen los programas, por ello ha de responder a concepciones filosóficas, psicológicas y pedagógicas que propicien la aplicación propia de los estudios.

Lo anterior supone que el alumno pueda comprender, es decir captar, atribuir significados y significar, como parte de un proceso donde la comprensión sea punto indispensable relacionado e interceptado por la intención comunicativa específica de cada actividad para resolver convenientemente una estrategia que implica el proceso de enseñanzaaprendizaje.

El objetivo esencial de la asignatura Español-Literatura en séptimo grado es desarrollar las habilidades idiomáticas de los alumnos y la competencia comunicativa, lo que se logrará a medida que se convierta en un comunicador eficiente, en este sentido ocupa un lugar importantísimo la comprensión de textos.

Al respecto se destaca como el proceso que dicho componente significa, que, según García, E. (1978: 42) está dado en "entender, penetrar, concebir, alcanzar, discernir, descifrar (decodificar)", es decir, destejer significados y reconstruirlos, a partir de lo aportado por el texto, donde cada lector hará una lectura "individual", condicionada por su concepción del mundo, conocimiento del tema y competencias de que dispone.

Los procesos cognoscitivos están estrechamente relacionados con los contenidos referidos y han de analizarse de forma lógica en lo ontológico, esfera del ser y en lo axiológico, esfera de los valores.

La escritora Aguirre, M. (1989: 58) señala que: "el lector puede entender el texto mejor que el autor, pues lo reconstruye y desde su aquí, desde su ahora y enriquece su mundo".

Este criterio pedagógico se basa en el modelo didáctico del enfoque cognitivo, comunicativo y sociocultural por el cual se revela su verdadero significado y sentido, el vínculo entre el medio social y el proceso pedagógico entre sus componentes.

La comprensión se nos presenta entonces, en comunicación cotidiana como una de las trabas principales la perspectiva por parte del sujeto que aprende y se prepara para la vida, el grado de concientización imprescindible en relación con su formación personal.

En consonancia con lo anterior, al realizar la búsqueda en los postulados de Vygotsky, L. S. (1989: 104). Se verifica que el desarrollo psicológico no es posible sin la instrucción, de ahí la importancia que tuvo para él, la instrucción en el desarrollo de las funciones psicológicas superiores.

Alonso, J. (1993: 79) "la comprensión del texto es el producto final de la lectura y depende simultáneamente de los datos proporcionados por este y de los conocimientos de distintos tipos que posee el lector".

De igual forma para Dubois, M. (1996: 35) la comprensión: "es un proceso de interacción entre pensamiento y lenguaje en que la comprensión es la construcción del significado del texto por parte del lector".

Ambas ideas resaltan la importancia que reviste la enseñanza de la comprensión como prueba que respalda de igual forma lo esencial: el intercambio de significados.

Zilberstein, J. (2000: 72) asume que: "la habilidad se desarrolla en la actividad y que implica el dominio de la actividad cognoscitiva, práctica y valorativa, es decir, el conocimiento en acción”. 
Desde el punto de vista psicológico, se sustenta aquí el aprendizaje como proceso interactivo, dialéctico, en el que intervienen los conocimientos, las experiencias y las vivencias del estudiante como sujeto activo, irrepetible, social y protagonista, en el que se producen modificaciones en su actividad.

Dicho autor centra su atención en las estrategias metacognitivas para facilitar el aprendizaje útil y potenciador de ideas que permitan que el estudiante sea sujeto de su propio aprendizaje, al ser la metacognición un proceso individual y complejo que constituye una actividad cognoscitiva planificada y autocontrolada con la intervención de la memoria, la atención, la imaginación, el pensamiento y la acción. De ahí que se pone de manifiesto en la propuesta de actividades la relación sujeto-objeto-sujeto y sujeto-objeto.

En lo sociológico se parte del carácter histórico-social, lo que releva la importancia del medio social en el desarrollo del individuo. El estudiante debe sentirse apropiado de su sentir, pensar y actuar en diversos contextos, lo que adquiere relevancia en el proceso de desarrollo cultural concretándose entre educación, sociedad e individuo.

Addine, F. (2003: 168) concibe la comunicación como un proceso de intercambio de información a través de signos, mediante el cual se comparten experiencias, conocimientos y vivencias lográndose una influencia mutua.

Roméu, A. (2003: 21) en su libro Teoría y Práctica del análisis del discurso. Su aplicación en la enseñanza, define que: "La comprensión consiste en un proceso de atribución de significados al texto", criterio que asume la autora del presente trabajo pues resulta incuestionable que la comprensión se hace efectiva cuando el lector es capaz de interiorizar el texto a través de los tres significados: literal o explícito, intencional o implícito y el complementario o cultural.

Por otra parte, también se percibe su estructura semántica (significados), lingüística (medios fónicos, léxicos, morfosintácticos, entre otras, con lo que se construye el significado) y pragmática (intención y finalidad comunicativas) el lector es capaz de aplicar al texto una comprensión global. La comprensión está relacionada con el conocimiento de lo inferido en el texto, en la medida que se tengan determinados conocimientos; por eso quien está dotado de conocimientos comprende mejor.

Todo texto, según apuntan diversos autores (García Alzola, Angelina Roméu y otros), es portador al menos de tres significados:

1. Literal o explícito: Es lo que se expresa de manera directa en el texto.

2. Intencional o implícito: No se dice literalmente, pero se descubre entre líneas, subyace en el texto. Una vez descubierto, se hace también explícito.

3. Complementario o cultural: Se expresa en la riqueza léxica, profundidad del contenido, cultura general y experiencia del autor reflejada en lo que el texto significa (tratamiento del tema, vocabulario, entre otros). Al escuchar a una persona o al leer un escrito, si se posee un buen nivel de comprensión se estará en condiciones de captar tanto lo que el autor dice de manera explícita como implícita, de acuerdo con su universo del saber. La asimilación de los significados citados anteriormente es esencial para poder lograr la lectura inteligente, crítica y creadora del texto que le va a permitir al lector una mejor comprensión global del mismo.

Desde el punto de vista didáctico, la comprensión de textos ha sido trabajada como la construcción de red de representaciones mentales; como superación de las limitaciones cognitivas que enfrenta el estudiante en el proceso de aprendizaje.

Diversos investigadores opinan que el lector atraviesa por tres niveles de comprensión textual. La búsqueda e indagaciones bibliográficas permiten detectar la multiplicidad de posiciones al respecto; sin embargo, el análisis percibido, muestra que entre ellos hay elementos semejantes. Estos son los criterios:

Para Domínguez, I. (2010: 154) el proceso de comprensión transcurre en tres niveles:

1. La comprensión inteligente: Tiene lugar en este nivel la captación del significado literal. A esta etapa se denomina también etapa de traducción, que implica no solo captar lo que el texto significa, sino, también atribuirle significado a partir sus conocimientos, experiencias. En esta etapa, el lector capta los significados literales (lo que dice explícitamente), intencional o implícito (lo que se dice entre líneas) y complementario (lo que necesita de los saberes que el lector posee: vocabulario, cultura, experiencias personales).

2. La comprensión crítica: En este nivel el lector asume una actitud de aceptación o rechazo hacia el contenido del texto. Para ello opina, enjuicia, comenta, valora y toma partido a favor o en contra.

3. La comprensión creadora: En este tercer y último nivel el lector aplica el texto a otros contextos, ejemplifica y extrapola. Relaciona con otros textos que ya conoce e inserta esos significados a su universo del saber conectándolos entre sí de manera armónica.

Montaño, J. R. (2010: 381), cita a Pérez A, M quien reconoce como niveles de comprensión textual los siguientes: 
1. Nivel de lectura literal/comprensión localizada: Se evalúa aquí, principalmente, las competencias semánticas y gramaticales o sintácticas. En este nivel se indagan tres procesos básicos:

* El reconocimiento de sujetos, eventos u objetos, mencionados en el texto, o del significado literal de una palabra, una frase, un signo, etc., a manera de transcripción.

* La paráfrasis, entendida como la traducción del significado de una palabra o frase empleando sinónimos o palabras distintas sin que se altere el significado literal.

* La identificación de las relaciones entre los componentes de un párrafo o dentro de una oración.

2. Nivel de lectura de tipo inferencial/Comprensión global: En este nivel se explora la posibilidad de realizar inferencias, entendida como la capacidad de obtener información o establecer conclusiones que no están dichas de manera explícita en el texto al establecer diferentes tipos de relaciones entre los significados de las palabras, oraciones y párrafos. Implica una comprensión global de los significados del texto y el reconocimiento de esas relaciones, funciones y nexos entre las partes del texto: relaciones temporales, espaciales, causales. Aspectos como la coherencia y cohesión son centrales en este nivel. En el proceso de inferir información también se ponen en juego los saberes con que cuenta el lector, así como la posibilidad de identificar el tipo de texto (narrativo, argumentativo, expositivo).

3. Nivel crítico-intertextual/Lectura global del texto: En este nivel se explora la posibilidad de que el lector tome distancia del contenido del texto, de manera que asuma una posición ante lo expresado. Supone la elaboración de un punto de vista. Para poder llegar al nivel de lectura crítica es necesario identificar las intenciones del texto, autores o narradores presentes en estos. También es necesario reconocer las características del contexto en que están implícitas estas intenciones, percibidas por los lectores a través de una especie de diálogo que hace posible establecer relaciones entre el texto leído y otros.

Desde los niveles de comprensión por los cuales transita el proceso lector, es evidente distinguir un proceso ascendente que va de un nivel más literal a uno más profundo. Es, en tal sentido que, a consideración de las autoras, la mayoría de los autores consultados distinguen que el proceso de comprensión de textos transita por estos tres niveles:

I- Nivel Traducción: En el que el lector descubre los significados del texto que lee y que responde a la pregunta ¿Qué dice el texto?

Está asociado a la comprensión del significado literal, implícito y complementario o cultural del texto que se lee. Este nivel se puede medir a partir del reconocimiento de lo que el texto comunica explícita o implícitamente, de la determinación del tema, reconocimiento de los personajes, ambiente y argumento, de la identificación de la estructura interna y externa del texto, del reconocimiento de la tipología textual a la que el texto pertenece y de las formas elocutivas que en el predominan, así como la identificación de sentimientos, actitudes y valores que comunica el texto en establecer inferencias y relación de diversas cuestiones. Por último, en este nivel se deben establecer inferencias y relaciones de diversa naturaleza que se corresponde con una lectura inteligente.

II- Nivel Interpretación: Responde a la pregunta ¿Qué opino del texto? o ¿Qué valoración puedo hacer de su contenido o de su mensaje?

Se corresponde con la lectura crítica y en él se deben establecer relaciones, alumno analiza, reflexiona, enjuicia, valora el contenido y la forma del texto, emite criterios personales de valor y argumentos al reconocer el sentido profundo del texto que lee.

III- Nivel Extrapolación: Responde a la pregunta: ¿Para qué me sirve el texto?

Se relaciona con la lectura creadora, implica el establecimiento de relaciones entre el texto leído y otros textos (lectura intertextual), ya sea por tema, por el estilo, por la tipología textual a la que pertenece o por otros aspectos susceptibles de compararlo. Asimismo, ofrece la vigencia o actualización de su contenido y mensaje con respecto a otras realidades, a otras experiencias, aplica creadora mente a nuevas situaciones lo leído, reacciona ante ello y última instancia, puede modificar su conducta personal.

En este nivel se pueden y deben desarrollar actividades tales como (crear título para el texto, escribir un comienzo o un final diferente, escribir o rescribir el contenido del texto, pero ajustándolo a otra tipología textual y añadir o suprimir elementos como: detalles, personajes, lugares determinantes e ideas).

Para dar cumplimiento a estas interrogantes planteadas en el proceso de comprensión deben cumplirse diferentes fases o etapas, tales como: 
- Actividades de motivación para la lectura: Al planificar y organizar las actividades docentes, se motiva con acciones alusivas al contenido del texto, a la preparación para la lectura, la cual permite la creación de un clima psicológico positivo, de estimulación hacia la tarea de aprendizaje.

- Actividades de pre-lectura: que implican un acercamiento al texto en un primer nivel de comprensión. Esta fase coincide con la orientación de la tarea de aprendizaje que es la base orientadora de la acción y comprensión de la tarea a realizar.

* Actividades de comprensión: En este momento se trabaja con preguntas de los tres niveles de desempeño cognitivo y fundamentalmente debe prevalecer la lectura crítica y reflexiva la cual consiste en enjuiciar los valores formales y de contenido del texto en cuestión a través de la interpretación de las ideas fundamentales. La lectura consciente constituye un verdadero diálogo entre texto y lector. Es recomendable que el docente propicie el intercambio, discusión y confrontación de lo realizado y del análisis de la tarea en cada uno de los alumnos y del grupo en general y que esta tenga un carácter evaluativo.

* Actividades de aplicación: En esta fase los alumnos aplican los conocimientos a un nuevo contexto, o establecen relaciones intertextuales, por lo que predomina la lectura creadora y el tercer nivel de desempeño cognitivo.

Estas fases deben planificarse siempre, lo que no implica que en todas las clases tengan que estar presentes de la misma forma. Puede que en una actividad docente se transite por todas ellas, pero quizás en otra, por sus características, todo el tiempo se dedique a la orientación o a la realización de la tarea.

Es importante abordar la relación que tiene la comprensión lectora con otros tipos de comprensión entre la que se destaca la comprensión metacognitiva, directamente relacionada con el grado de autoconocimiento que el lector posee de sus propios procesos de comprensión y que adquiere en el proceso de lectura, recepción e interpretación un valor funcional incalculable, pues le permite al individuo saber a cada instante si el estudio de un fenómeno que necesita comprender requiere de un mayor o menor número de recursos cognitivos.

En esencia, el tratamiento didáctico a la comprensión como componente funcional exige dotar a los estudiantes de un conjunto de estrategias cognitivas y metacognitivas que le faciliten una mejor interpretación de lo leído. Teniendo en cuenta este planteamiento resulta necesario definir las categorías estrategias, cognición y metacognición.

Estrategias: Son procedimientos o herramientas que se llevan a cabo en el proceso de enseñanza-aprendizaje para lograr el objetivo de construir significados a partir de la interpretación de los textos leídos. Las estrategias tienen gran incidencia en la comprensión lectora, se emplean con el objetivo de comprender lo que se lee, de esta forma el lector obtiene la información contenida en los textos y la procesa en función de lograr la meta propuesta.

Cognición: Esta categoría se define como una síntesis de comunicación y actividad, realizada con la intervención del lenguaje que participa, tanto en la construcción del pensamiento como en su transmisión en el proceso de interacción comunicativa. Además, la cognición puede ser entendida por los conocimientos, habilidades, capacidades; relacionadas con el procesamiento de información que la persona tiene para comprender y producir los significados.

Metacognición: Comprende el conocimiento que cada cual posee acerca de sus propios procesos cognitivos; tiene que ver con las ideas sobre el proceso de cognición y los resultados de dicho proceso. Se considera que la metacognición tiene dos componentes: el conocimiento referido a la cognición y el de la regulación de la cognición.

El estudiante que no posee las estrategias cognitivas y metacognitivas precisas no es un lector estratégico. Un lector estratégico piensa y reflexiona mientras lee, está consciente de las acciones u operaciones mentales que realiza, para qué y por qué las hace y es capaz de buscar soluciones para corregir las barreras que impiden comprender. El papel del lenguaje en este sentido es fundamental porque posibilita verbalizar o exteriorizar lo que piensa.

1. El tratamiento metodológico de la comprensión de textos debe seguir una secuencia básica tratada desde la clase.

2. Percepción del texto (lectura o audición).

3. El reconocimiento de palabras claves.

4. Determinación de los núcleos de significación o ideas principales (proposiciones temáticas).

5. Aplicación de estrategias de comprensión.

6. Comprensión del texto ateniendo a los tres niveles de (traducción, interpretación y extrapolación).

7. Determinación del tema o asunto.

8. Resumen de la significación del texto mediante diferentes técnicas: (construcción de un párrafo).

9. Proposición de un título. 
Es importante destacar también que el desarrollo de la comprensión de textos de contenido medioambiental es vía indiscutible para el tratamiento de la Educación Ambiental como proceso educativo sistémico y sistemático que trasciende la enseñanza, y se orienta a la formación de la conciencia y el desarrollo de motivaciones, sentimientos, habilidades, capacidades y hábitos en los estudiantes.

También determina la manifestación de convicciones, conductas y actividades participativas en favor de la impostergable necesidad de proteger el medio ambiente. En este sentido, cabe resaltar que el aprendizaje, en su orden más general, puede definirse como la adquisición de una nueva conducta, a consecuencia de su interacción con el medio externo. Aprender, como se conoce, es la condición más importante para la vida del hombre.

En esto se basa la necesidad de una educación cuya finalidad no sea solamente la de informar, transmitir conocimientos; formar hábitos, habilidades, valores; sino que también se cree una conciencia acerca del impacto de la actividad humana sobre el medio ambiente, entre otras; en cuyo propósito se involucre a toda la población, comenzando por los más jóvenes que tenemos hoy en las escuelas: los adolescentes de Secundaria Básica.

Estas consideraciones permiten reflexionar acerca de las ideas de Castro, F. (1992), en su discurso en la Cumbre de Río, cuando expresa: "Una especie biológica está en riesgo de desaparecer por la rápida y progresiva liquidación de sus condiciones naturales de vida: el hombre".

Desde 1992 hasta la actualidad se han efectuado disímiles Fórum, Congresos, con propuestas en el orden internacional para atender este reclamo del líder de la Revolución, unas cumplidas y otras no, pero la situación continúa agravándose, pues los países que más pueden hacer al respecto son los que menos apoyan dado que afecta sus intereses económicos.

En Cuba se desarrollan diversas acciones en aras de aminorar el deterioro ambiental por parte de todos los organismos y empresas. El Ministerio de Ciencia Tecnología y Medioambiente tiene diseñado todo un programa encaminado a toda esta transformación y el Ministerio de Educación concibe programas de Educación Ambiental entre los objetivos de la educación de niños, adolescentes y jóvenes.

Según Novo, M. (2011: 5) “(...) La Educación Ambiental ha sido creada y difundida por el mundo con un nuevo enfoque educativo, producto de la perfección del hombre de que esté inmerso en una crisis ambiental provocada por el mismo y que solo él podrá solucionarlo".

De esta manera se involucra también a la comunidad de donde viene la materia prima con la que trabaja el profesor. La Educación Ambiental constituye un proceso permanente que alcanza todos los ámbitos educativos formales y no formales. La escuela como factor supremo de la sociedad es la encargada de la Educación Ambiental, de ahí que maestros y profesores se superan en esta dirección y conciben proyectos, estrategias, actividades que favorecen la sensibilidad y conciencia respecto al medio ambiente.

Según el Diccionario Pequeño Larousse (1968: 19) se define la actividad como: facultad de obrar. diligencia, eficacia. Conjunto de operaciones o tareas propias de una entidad o persona. Desde el punto de vista de la profesión se atiende la actividad docente.

Las actividades son herramientas para potenciar el perfeccionamiento del trabajo y conducción del proceso de enseñanza-aprendizaje dirigido al logro de un resultado en consecuencia con el contexto para el cual son concebidas.

Es de esta forma que, en sí, la información necesaria en cuanto a niveles de desempeño se refiere y el dominio cognitivo, facilitan el desarrollo del aprendizaje en los estudiantes. Las actividades que en el trabajo se proponen, su contenido encierra un mensaje tanto de forma explícita como implícita para el logro de la comprensión de textos de contenido medioambiental para la clase.

Las siete actividades que se proponen en este trabajo en relación con la comprensión de textos de contenido medioambiental presentan la estructura siguiente: fecha, temática, objetivo, medios, orientaciones metodológicas, técnica de cierre, texto y actividades que están graduadas por los diferentes niveles de asimilación. De igual manera se evaluará la comprensión de lo leído de forma cuantitativa. 
Actividades que contribuyen a la comprensión de textos de contenido medio ambiental en los estudiantes de séptimo grado.

\section{* Actividad No. 1}

Fecha: octubre, en conmemoración a la desaparición física del Che.

Temática: Yo cuido los árboles.

Objetivo: Interpretar fragmentos del poema "La Higuera" evidenciando el respeto y cuidado por la protección de los árboles y la flora cubana.

Medios: Libro de texto de séptimo grado de Español Literatura.

\section{Orientaciones metodológicas:}

- Se aprovechará el texto seleccionado para enmarcar la recordación histórica que posee el título del poema.

- Leer en alta voz y con la expresividad adecuada por un buen lector del poema.

- Realizar la lectura comentada por varios estudiantes del texto.

- Analizar las palabras de difícil comprensión para entender lo que se lee.

- Reflexionar a partir de las actividades indicadas a que los estudiantes evidencien el respeto y protección de los árboles, que constituyen parte de la flora cubana.

Técnica de cierre: Para la evaluación final de la actividad, se le entregarán tarjetas en blanco para que cada uno de los estudiantes emita su criterio.

\section{Texto No.1}

La Higuera.

Porque es áspera y fea,

porque todas sus ramas son grises,

yo le tengo piedad a la higuera.

En mi quinta hay cien árboles bellos:

ciruelos redondos,

limoneros rectos

y naranjos de brotes lustrosos.

En las primaveras,

todos ellos se cubren de flores

en torno a la higuera

Y la pobre parece tan triste

con sus gajos torcidos que nunca

de apretados capullos se visten.

Por eso,

cada vez que paso a su lado

digo procurando

hacer dulce y alegre mi acento:

-Es la higuera el más bello

de los árboles todos del huerto.

Si ella escucha,

si comprende el idioma en que hablo,

iqué dulzura tan honda hará nido

en su alma sensible de árbol

Y tal vez, a la noche,

cuando el viento abanique su copa,

embriagada de goce le cuente:

- ¡Hoy a mí dijeron hermosa!

1. Lee en voz alta, con la expresividad adecuada, el siguiente poema de la uruguaya Juana de Ibarbourou y responde las actividades que se te indican.
a. Es un texto: literario
b. Está escrito en: prosa no literario verso 
c. Este poema pertenece al género: _épico_ lírico__ dramático

d. ¿Conoces el significado de todas las palabras que aparecen en el poema?

2. En el texto se plantea que:

La higuera abunda en nuestros campos.

La higuera brinda hermosos frutos.

La higuera posee sus gajos torcidos.

La poetisa siente pena por la apariencia física de la higuera.

3. El título del texto se relaciona con el lugar específico donde murió una de las personalidades históricas. Menciona a quien se está haciendo alusión.

4. ¿Por qué crees qué la autora plantea qué le tiene piedad a la higuera?

5. ¿Consideras qué la higuera por ser un árbol "áspero y feo" carece de importancia? Argumenta tu respuesta.

6. La autora plantea que en su quinta hay hermosos árboles frutales. ¿A qué se debe esto?

7. Puedes mencionar algunas de las medidas de cuidado y protección de los árboles que conozcas.

8. Las siguientes palabras son derivadas. Explica por qué lo sabes.

Limonero dulzura

a. Busca y escribe dos palabras de la misma familia de las anteriores.

b. Redacta dos oraciones con dos de la nueva familia que formaste.

9. Redacta un párrafo de carácter expositivo que responda a algunos de los siguientes comienzos.

Los árboles son fundamentales para el bienestar ecológico de la tierra...

Su desaparición pone en peligro el equilibrio medioambiental...

Control: Se pasará por los asientos y se mandará a la pizarra a los estudiantes.

Evaluación: responde a comprensión de lo leído, se evalúa a los estudiantes de forma cualitativa durante el desarrollo de la actividad y cuantitativa con una escala de (0- 10 puntos) para el cierre de la misma.

\section{* Actividad No.2}

Fecha: noviembre, en recordación al líder histórico de la Revolución Cubana.

Temática: ¿Viviremos en un mundo mejor?

Objetivo: Interpretar el impacto de las palabras pronunciadas por el Comandante en Jefe Fidel Castro Ruz en la Cumbre de Río, relacionado con los problemas medioambientales.

Medios: Hojas de trabajo (diapositivas) en la que aparece el texto seleccionado.

\section{Orientaciones metodológicas:}

- Realizar la lectura expresiva por el profesor del texto seleccionado. (Ver hojas de trabajo, anexo 6).

- Leer en silencio y con detenimiento el texto.

- Buscar el significado de las palabras escogidas del texto con dificultad en su significado, con ayuda del contexto y de ser necesario apoyarse del diccionario.

- Reflexionar a partir de las diferentes actividades previstas, logrando así el vínculo e interés de los estudiantes hacia una cultura ambientalista.

Técnica de cierre: Concluida la actividad los estudiantes podrán referir su opinión mediante una frase.

Texto No. 2

“... Si se quiere salvar a la humanidad de la autodestrucción, hay que distribuir mejor las riquezas y tecnologías disponibles en el planeta. Menos lujo y menos despilfarro en unos pocos países para que haya menos pobreza y menos hambre en gran parte de la tierra. No más transferencia al Tercer Mundo de estilos de vidas y hábitos de consumo que arruinan el medio ambiente. Hágase más racional la vida humana. Aplíquese un orden económico racional justo. Utilícese toda la ciencia necesaria para un 
desarrollo sostenible sin contaminación. Páguese la deuda ecológica y no la deuda externa. Desaparezca el hambre y no el hombre..."

Castro, F. (1992)

1 Lea detenidamente el texto seleccionado y responda las actividades que se te indican.

¿Qué tema aborda el párrafo seleccionado?

2 Busca el significado de los siguientes vocablos extraídos del texto.

- autodestrucción - riquezas - despilfarro

- pobreza - transferencia - estilos de vida

3 En el texto se plantea: No más transferencias al Tercer Mundo de estilos de vidas y hábitos de consumo que arruinan el medio ambiente". Porque:

_ Necesidad de garantizar un adecuado estilo de vida de la humanidad.

_ Distribución de las riquezas en países desarrollados.

_ Influencias de las riquezas tecnológicas en el planeta.

4 ¿Qué posición asume Cuba respecto algunos de estos problemas que hoy en día afectan al medio ambiente?

5 Enlaza la columna A con la columna B, teniendo en cuenta los prefijos y sufijos para la formación de sustantivos derivados.

$\begin{array}{cc}\text { Columna A } & \text { Columna B } \\ \text { Sub } & \text { destrucción } \\ \text { Auto } & \text { desarrollo } \\ \text { Contra } & \text { planeta } \\ \text { Ario } & \text { orden }\end{array}$

a. ¿Qué le aportan estos sufijos y prefijos a la nueva palabra que formaste?

b. Redacta una oración bimembre en la que emplees uno de los sustantivos derivados que formaste.

6 ¿Consideras en tu condición de pionero, que pudieras contribuir a la protección y cuidado de tu medio ambiente? Expresa tu opinión a través de un párrafo de carácter expositivo.

Control: Se pasará por los asientos y se mandará a la pizarra a los estudiantes.

Evaluación: responde a comprensión de lo leído, se evalúa a los estudiantes de forma cualitativa durante el desarrollo de la actividad y cuantitativa con una escala de (0-10 puntos) para el cierre de la misma.

\section{Actividad No.3}

Fecha: diciembre, en conmemoración del día Mundial de la Biodiversidad.

Temática: Nuestra principal tarea.

Objetivo: Interpretar un texto seleccionado del Cuaderno de Actividades Ortografía vinculado con la diversidad biológica que propicie la necesidad de preservar el medio ambiente.

Medios: Cuaderno de Actividades Ortografía de séptimo grado de Español Literatura.

\section{Orientaciones metodológicas:}

- Localizar el Cuaderno de Actividades Ortografía, Temario 1, el texto seleccionado

- Realizar la lectura expresiva por el profesor y luego por varios estudiantes.

- Buscar las palabras de difícil comprensión.

- Analizar el texto seleccionado a través de las actividades que se proponen. 
Técnica de cierre: Se les dará la palabra a varios estudiantes para que con una palabra expresen su opinión.

\section{Texto No. 3}

La pérdida de la diversidad biológica es uno de los signos más preocupantes e irreversibles de los cambios globales que tienen lugar en la biosfera. Para Cuba es también uno de los cinco principales problemas ambientales.

La variedad vegetal del archipiélago se considera extraordinaria. Su flora es la más rica del Caribe y una de las diez más valiosas entre todos los sistemas insulares del mundo.

Exhibe unas 7020 especies de planetas vasculares, con un 50 por ciento de endemismo.

Del total, cerca de 14 por ciento está amenazado, por lo que constituye un patrimonio digno de conservarse más aún por pertenecer a un ecosistema vulnerable a cualquier cambio.

1 Lee con atención el siguiente texto y responde lo que se te pide a continuación.

a. ¿A qué problema medioambiental se está haciendo referencia en el texto?

2 Busca el significado de las palabras que ofrece dificultad para comprender el texto, por el contexto y de ser necesario utilice el diccionario.

3 Cuáles son las razones qué se dan en el texto para considerar que nuestra diversidad biológica es un patrimonio digno de conservar.

4 Son necesarios las leyes de protección de la diversidad biológica. Como puedes ayudar a que reconozcan y se respeten estas leyes.

5 Señala cuál d las siguientes reservas de la biosfera pertenece al territorio de tu provincia.

_ Península de Guanahacabibes. Buenavista. Sierra del Rosario. Baconao.

_Ciénaga de Zapata. Cuchillas del Toa.

6 Extrae la oración que te indica que la diversidad biológica constituye uno de los problemas medioambientales en nuestro país.

a. Extrae sus miembros fundamentales.

b. Clasifícala por el número de miembro.

7 Redacta un párrafo de carácter descriptivo en el qué expreses cómo se observa la diversidad biológica en la localidad donde se encuentra tu escuela.

Control: Se pasará por los asientos y se mandará a la pizarra a los estudiantes.

Evaluación: responde a comprensión de lo leído, se evalúa a los estudiantes de forma cualitativa durante el desarrollo de la actividad y cuantitativa con una escala de (0-10 puntos) para el cierre de la misma.

\section{Actividad No. 4}

Fecha: enero, en conmemoración al natalicio del Héroe Nacional José Martí.

Temática: América y su naturaleza.

Objetivo: Interpretar un fragmento seleccionado del Escrito Patriótico "Antonio Maceo" para consolidar una cultura ambientalista.

Medios: Cuaderno Martiano II, Escrito Patriótico "Antonio Maceo"

\section{Orientaciones metodológicas:}

- Localizar el Cuaderno Martiano II, Escrito Patriótico Antonio Maceo página 27, fragmento seleccionado.

- Realizar la lectura expresiva por el profesor y luego en silencio por los estudiantes.

- Buscar las palabras de difícil comprensión.

- Interpretar el fragmento seleccionado a través de las actividades que se proponen.

Técnica de cierre: Se les dará palabra a dos o tres estudiantes para que expresen su opinión. 


\section{Texto No. 4}

La naturaleza americana, doncella en el istmo, es ya hermosura próvida, y como de amplios senos, en el dominio de Costa Rica que se levanta por sobre las nubes, con sus troncos de sangre serpeando por el celaje azul, y derrama a las costas encendidas, por lecho siempre verde, el agua ancha y pedregosa de sus reventazones montañesas: como un himno es la república y cada hijo lleva la azada al hombro.

Allá del lado del Atlántico, por el río Matina, los plátanos son tan altos como la palma real, y es un cubano, que dio su sangre a Cuba, quien cría en la tierra amiga al platanal mejor...

1 Realiza la lectura comentada del texto seleccionado y determina lo que se te pide a continuación.

1.1- Atendiendo al lenguaje empleado en el texto se puede considerar como:

$$
\text { _ literario _ no literario }
$$

a. ¿Qué elementos te permiten afirmar tu selección?

2 Localiza el significado de las palabras subrayadas en el texto.

3 ¿Cuáles son los países qué se mencionan en el fragmento? ¿A qué continentes pertenecen?

4 ¿Qué palabras o expresiones de la naturaleza refleja Martí en su obra?

a. ¿De las palabras o expresiones mencionadas anteriormente cuál se considera un atributo nacional? ¿Por qué?

5 Extrae del texto los recursos expresivos del lenguaje literario que te ofrece el autor.

a. Clasifícalos.

b. Interpreta uno de ellos en tres renglones.

6 En el texto el autor expresa: los plátanos son tan altos como la palma real, y es un cubano, que dio su sangre a Cuba, quien cría en la tierra amiga el platanal mejor".

a. Redacte un texto en el que exprese el mensaje que encierra la expresión anterior.

Control: Se pasará por los asientos y se mandará a la pizarra a los estudiantes.

Evaluación: La comprensión de lo leído se evaluará de forma cuantitativa con una escala de (0-10 puntos).

\section{* Actividad No.5}

Fecha: febrero, dedicada al mes del amor.

Temática: Mi amiga el agua.

Objetivo: Interpretar un texto en verso relacionado con el agua para contribuir a la formación de sentimientos de amor y respeto por el medio ambiente.

Medios: Hojas de trabajo.

\section{Orientaciones metodológicas:}

- El profesor lleva en hojas de trabajo la poesía redactada por la estudiante de 7.o grado ganadora del concurso convocado por el (PAURA) Programa de Ahorro y uso racional del agua, titulado Tras agua.

- Se trabaja de forma colectiva en equipos.

- Cada integrante se familiariza con el texto luego de la lectura expresiva realizada por el profesor y de ser necesario pueden leer nuevamente.

- Buscar el significado de las palabras que ofrecen dificultad al comprender el texto por el contexto, y de ser necesario auxiliarse del diccionario.

- Reflexionar en cuanto a las ideas que les ofrece el texto, para garantizar la comprensión del mismo por los equipos.

Técnica de cierre: El profesor realizará una lluvia de ideas para concluir la actividad.

\section{Texto No. 5}

"Un recurso vital"

Agua dulce querida

Muestra de amor profundo 
Esencial para la vida

Y necesaria en el mundo.

Si de importancia se trata

Ella cogería lugar

Ya que importantes son todas

Las aguas en general.

El medio ambiente son luces

De inigualable belleza

Pero sin las aguas dulces

La madre naturaleza

Se volvería sombría

Pues estaría incompleta.

Como todo gran tesoro

Pronto se puede agotar

Ella vale más que el oro

¡La tenemos que cuidar!

1. Lee nuevamente el texto seleccionado y realiza las actividades que se te indican.

1.1 ¿A qué recurso natural se hace referencia en el texto?

a. ¿Qué palabras de difícil comprensión aparecen en el mismo, busca su significado?

b. ¿Qué título sugerente le pondrías a este poema?

c. ¿Cuántas estrofas y versos poseen el poema?

2 ¿Qué ideas te sugieren los dos primeros versos de la primera estrofa? Exprésalo por escrito.

a. ¿En el texto aparece el vocablo inigualable, con qué intención se ha utilizado el mismo?

3 ¿Por qué crees que se afirma que el agua resulta esencial para la vida y necesaria en el mundo? Fundamenta esta afirmación con tres razones.

4 Extrae del poema tres palabras con acento hiático.

a. Divídelas en sílabas y clasifícalas por su acentuación.

b. ¿Qué importancia le concedes a este acento?

5 Analiza la última estrofa y responde.

a. ¿Qué medidas lleva a cabo el Gobierno revolucionario cubano en aras de evitar el agotamiento de tan preciado líquido?

6 Debate con tus compañeros el mensaje que se encierra en los últimos versos del poema.

7 A través de un párrafo de carácter expositivo, arriba a que conclusiones pudiste llegar.

Control: Se pasa por los asientos y se manda a la pizarra a los estudiantes.

Evaluación: responde a comprensión de lo leído, se evalúa a los estudiantes de forma cualitativa durante el desarrollo de la actividad y cuantitativa con una escala de (0- 10 puntos) para el cierre de la misma.

\section{Actividad No. 6}

Fecha: marzo, en saludo al Día Internacional de la Mujer.

Temática: Cuidemos la flora.

Objetivo: Comprender el texto "La flor nacional" para desarrollar sensibilidad en los estudiantes respecto a la protección de la flora y fauna.

Medios: Libro de texto de Español Literatura, séptimo grado.

Orientaciones metodológicas:

- Leer expresivamente por un buen lector o el profesor el texto.

- Leer en silencio y con detenimiento el texto.

- Extraer las palabras del vocabulario que le resulte de difícil comprensión.

- Buscar el significado de las mismas, primero dentro del contexto donde se encuentran, luego de no precisarse, auxiliarse del diccionario 
- Analizar cada una de las preguntas desde la pizarra y con detenimiento, logrando que se dirija la actividad a despertar en los estudiantes el interés por el logro de una Educación Ambiental.

Técnica de cierre: Concluida la actividad los estudiantes expresarán su estado de ánimo, dándole color y significado a las flores que pinten.

\section{Texto No. 6}

Las flores siempre son portadoras de un mensaje especial. Los cubanos las obsequiamos en fechas tan señaladas coma el día de las madres, el día internacional de la mujer, el día del educador. También de modo muy significativo, las empleamos para rendir homenaje al Comandante Camilo Cienfuegos.

En Cuba existe gran variedad de flores, exquisitas por su perfume y de gran belleza y colorido; pero solo a una se le confiere el título de flor nacional de Cuba: a la mariposa blanca.

Entre los pétalos de la mariposa blanca, nuestras valerosas mujeres de las primeras luchas independentistas ocultaban mensajes para los mambises. Por esto, y por su delicada fragancia y belleza, se le concede el título de flor nacional, el 13 de octubre de 1936.

Esta flor abunda mucho en nuestro país, pero es originaria de Asía.

1 Luego de realizar la lectura detenidamente del fragmento, realiza las siguientes actividades.
a. El tema que trata el fragmento es sobre: _la fauna cubana __la flora cubana.

b. ¿Por qué el texto se plantea qué "las flores son portadoras de un mensaje especial?

c. ¿A qué se debe que en Cuba exista gran variedad de flores?

d. ¿Crees qué las flores necesitan de un ambiente propicio para su desarrollo? Fundamenta tu respuesta en tres renglones.

2 Forma una familia de palabras con cada una de las siguientes palabras.

$$
\text { _flor_madre _perfume }
$$

a. Realiza el análisis sintáctico de la siguiente oración simple.

Las flores son portadoras de un mensaje especial

3 Consideras que si el estado cubano no tomara medidas de protección con la flora cubana existiría en la actualidad gran variedad de flores

a. ¿Conoces algún lugar de tu provincia que esté dedicado al cuidado y protección de algunas especies de flores?

4 Imagina que eres "una mariposa blanca" y describe a través de un texto ¿cómo te gustaría que fuera el medio ambiente donde vivirías?

Control: Se pasará por los asientos y se mandará a la pizarra a los estudiantes.

Evaluación: responde a comprensión de lo leído, se evalúa a los estudiantes de forma cualitativa durante el desarrollo de la actividad y cuantitativa con una escala de (0-10 puntos) para el cierre de la misma.

\section{* Actividad No.7}

Fecha: abril, para el disfrute de vacaciones.

Temática: Sol, arena y mar. ¡Una delicia!

Objetivo: Describir sentimientos de amor y respeto por la naturaleza cubana a través de la comprensión del texto "Las playas de mi país"

Medios: Libro de texto de Español Literatura, séptimo grado.

\section{Orientaciones metodológicas:}

- Leer expresivamente por un buen lector o el profesor el texto.

- Leer en silencio y con detenimiento el texto.

- Extraer las palabras del vocabulario que le resulte de difícil comprensión. 
- Buscar el significado de las mismas, primero dentro del contexto donde se encuentran, luego de no precisarse, auxiliarse del diccionario.

- Analizar cada una de las preguntas desde la pizarra y con detenimiento, logrando que se dirija la actividad a despertar en los estudiantes el interés por el logro de una Educación Ambiental.

Técnica de cierre: Concluida la actividad se aplicará un PNI Positivo, Negativo e Interesante.

\section{Texto No. 7}

Las playas de mi país son deliciosas. Sus arenas son blanquísimas. La brisa invita al descanso. Sus aguas, de azul turquí, claman por el bañista. Cualquier atardecer en nuestras playas nos llena de nostalgia e inspiración.

1 Después de leer correctamente el texto responde las siguientes actividades.
a. Según el lenguaje empleado el texto es: _ literario No literario
b. ¿Qué palabras desconoces su significado?
c. ¿Cuál es la idea central que desarrolla el mismo?

2 Selecciona los elementos del texto que justifican el que se exprese que las playas de mi país son deliciosas.

a. ¿Qué parte de la oración es el vocablo deliciosas?

b. Sustitúyela por un sinónimo adecuado.

c. Extrae la primera oración gramatical, así como sus miembros básicos.

3 El autor plantea que: "La brisa invita al descanso"

a. ¿Pudieras descansar en una playa que no esté totalmente limpia de desechos y basuras de todo tipo? Fundamenta el planteamiento anterior en no más de cuatro renglones.

4 ¿Cómo imaginas que sería el medio ambiente donde estaría ubicada esta playa? Trata de expresarlo a través de la redacción de un párrafo.

Control: Se pasará por los asientos y se mandará a la pizarra a los estudiantes.

Evaluación: responde a comprensión de lo leído, se evalúa a los estudiantes de forma cualitativa durante el desarrollo de la actividad y cuantitativa con una escala de (0-10 puntos) para el cierre de la misma.

\section{CONCLUSIÓN}

Los fundamentos teóricos asumidos consideran: las concepciones en las que se sustenta la comprensión de textos, el aprendizaje como proceso interactivo en el que intervienen los conocimientos, las experiencias y las vivencias de los estudiantes, la importancia del trabajo de la escuela respecto a la Educación Ambiental, los que se concretan en las actividades propuestas para dar tratamiento a la comprensión de textos de contenido medioambiental.

El presente artículo brinda actividades que contribuyen a la comprensión de los diferentes textos seleccionados y a la vez constituye una herramienta para el maestro en el diseño de nuevas actividades que posibiliten la elevación de los niveles deseados en la comprensión de un texto.

La propuesta fue valorada de efectiva y pertinente, por especialistas experimentados, maestros y profesores, obteniéndose resultados positivos en el $100 \%$ de los estudiantes a los que fue aplicada, y puede ser generalizada en otros centros escolares en función de que se favorezca la comprensión de textos de contenido medioambiental.

\section{BIBLIOGRAFÍA}

1. Abello, A. M. y otros. (2004). Español. Séptimo grado. Cuaderno Complementario. La Habana: Editorial Pueblo y Educación,

2. Addine, F. (2004). Didáctica, teoría y práctica. La Habana: Editorial Pueblo y Educación.

3. (2003). Principios para la dirección del proceso pedagógico. En Ana María González y Silvia Recarey. En Compendio de Pedagogía. La Habana: Editorial Pueblo y Educación,

4. Aguirre, M. (1989). Estudios Literarios. La Habana: Editorial Letras Cubanas.

5. Alonso, J. (1993). La evaluación de la comprensión lectora, texto de didáctica de la Lengua y la Literatura. No. 5. Madrid.

6. Castro, F. (1992). Conferencia de Naciones Unidas sobre Medio Ambiente y desarrollo. Cumbre de Río de Janeiro. Tabloide Especial No.1. La Habana. 
7. Cerezal, J. y Fiallo, J. (2009). Como investigar en Pedagogía. La Habana: Editorial Pueblo y Educación.

8. Cuaderno Martiano II. (2010). Secundaria Básica. Selección de Cintio Vitier. La Habana: Editorial Pueblo y Educación.

9. Cuba. Ministerio de Educación. (2014). Programa de Español. Séptimo grado. La Habana: Editorial Pueblo y Educación.

10. Domínguez, I. (2010.). Comunicación y texto. La Habana: Editorial Pueblo y Educación.

11. : (2013). Lenguaje y Comunicación. La Habana: Editorial Pueblo y Educación.

12. Dubois, M. (1996). Estilística de la lengua. En Selección de lecturas para la comprensión. La Habana: Editorial Ciencias Sociales.

13. Eco, H. (1976). Tratado de semiótica General. Barcelona: Editorial Lumen.

14. García, E. y otros. (1978). Metodología de la enseñanza de la lengua. La Habana: Editorial Pueblo y Educación.

15. García, D. (2001): La enseñanza de la lengua materna en la escuela primaria. La Habana Editorial Pueblo y Educación.

16. Gutiérrez, M. (2018). El tratamiento a la lengua materna en la enseñanza primaria: Vías para su aplicación desde la comprensión de textos. Compilación. Santiago de Cuba: Universidad de Oriente.

17. Luz y Caballero, J. (1991). Escritos Educativos. La Habana: Editorial Pueblo y Educación.

18. Mañalich, R. y coautores. (1999). Taller de la palabra. La Habana: Editorial Pueblo y Educación.

19. Martí, J. (1991). Obras completas. T. 6, 8, 13, 17, 19. La Habana: Editorial Ciencias Sociales.

20. Martí y la educación (1996). La Habana: Editorial Pueblo y Educación.

21. Montaño, J. R. (2015). Leer y escribir: jtarea de todos!. La Habana: Editorial Pueblo y Educación.

22. . (2010). Renovando la enseñanza-aprendizaje de la lengua y la literatura. La Habana: Editorial Pueblo y Educación.

23. Montesinos, J. R. y otros. (2009). Español. Séptimo grado. Cuaderno de actividades. Ortografía. La Habana: Editorial Pueblo y Educación.

24. Novo, M. (2011). La Educación Ambiental en el marco del paradigma ambientalista. La Habana.

25. Pérez, M. (1999). Evaluación de competencias en comprensión de textos. iqué evalúan las pruebas masivas en Colombia! Alegría de enseñar. Año 10. No.39. Colombia.

26. Pequeño Larousse llustrado. (1968).Diccionario enciclopédico. Instituto del Libro. La Habana.

27. Rodríguez, R. (2011). La educación ambiental en el proceso docente-educativo de la Secundaria Básica en Cuba. Compilación. La Habana: Editorial Pueblo y Educación.

28. Rodríguez, L y otros. (2009). Español Literatura. Séptimo grado: La Habana. Editorial Pueblo y educación.

29. Rodríguez, M. (2013). Papel de la comunicación en la labor de los instructores de arte. [CD-ROOM]. IV Taller Regional de Lengua Materna. Guantánamo. UCP.

30. Roméu, A. (2007). El enfoque cognitivo, comunicativo y sociocultural en la enseñanza de la lengua y la literatura. Compilación: La Habana. Editorial Pueblo y Educación.

31. (2003). Teoría y práctica del análisis del discurso. Su análisis en la enseñanza: La Habana. Editorial Pueblo y Educación.

32. Vygotski, L. S. (1989). Pensamiento y lenguaje: La Habana. Editorial Pueblo y Educación.

33. Zilberstein, J. (2001). Calidad educativa y diagnóstico del aprendizaje escolar. Pedagogía Curso. La Habana, IPLAC. 